STUDIA ROSSICA POSNANIENSIA, vol. XLII: 2017, pp. 319-327. ISSN 0081-6884.

Adam Mickiewicz University Press, Poznań

\title{
ПРОБЛЕМЫ ПОВЫШЕНИЯ ЭФФЕКТИВНОСТИ ПРЕПОДАВАНИЯ ИНОСТРАННЫХ ЯЗЫКОВ И НЕКОТОРЫЕ АСПЕКТЫ СОЦИАЛЬНОЙ ЛИНГВОДИДАКТИЧЕСКОЙ ТЕОРИИ
}

\author{
THE PROBLEMS OF INCREASING THE EFFECTIVENESS OF TEACHING \\ FOREIGN LANGUAGES AND SOME ASPECTS OF SOCIAL \\ METHODOLOGY IN LANGUAGE TEACHING
}

\author{
STANISŁAW SIATKOWSKI
}

\begin{abstract}
The article opens with a discussion of the main educational and organizational reasons, as well as other circumstances (for example, the lack of publicly entitled language policy in the country) for the relatively low effectiveness of recent teaching of foreign languages, in particular Russian language, in comparison to some highly developed countries in Western Europe. The author goes on to introduce the significant current substantive (scientific) issues of the new approach to a practically oriented theory of teaching foreign languages - social glottodidactics.
\end{abstract}

Stanisław Siatkowski, Uniwersytet Warszawski, Warszawa - Polska.

К главным причинам все еще относительно низкой эффективности и заметного отставания в области преподавания иностранных языков в Польше в сравнении, например, с высокоразвитыми западноевропейскими странами относятся недостатки, связанные с не всегда удовлетворительной подготовкой преподавательских кадров, не вполне компетентным проектированием лингводидактического процесса (в программах обучения, соответствующих пособиях для преподавателя, учащихся и т. п.), нередко низким уровнем его реализации, причем не только в аудиторных условиях, но и с недостаточно дооцененным управлением преподавателями индивидуальным, внеаудиторным самообучением языку с использованием современных технических и других средств и возможностей. Кроме того, существует не менее важная проблема решения комплекса различных вопросов создания по возможности оптимальных в существующих условиях предпосылок для внедрения концепционно обоснованной, синергетически организованной системы и стратегии преподавания, охватывающей соответствующие его уровни и виды - дошкольное (что очень важно), школьное, вузовское, а также разные другие вспомогательные, в частности краткосрочные формы обучения. 
При всем этом практически нет у нас надлежащим образом продуманной актуальной и перспективной языковой политики, как внутренней, так и внешней, учитывающей соответствующие страны и регионы мира. Этот последний вопрос почему-то публично не обсуждается в Польше в отличие от ряда других стран. Хотя Польшу нельзя сейчас назвать многонациональным государством, в котором эта политика отличалась бы большой сложностью и играла бы весьма существенную роль, то в каждом государстве она должна существовать и учитываться в системе образования. Особенно сегодня, когда мир стал превращаться, как говорится, в одну большую деревню, преподавание и усвоение языков стало ценным товаром как в жизни общества, так и в жизни отдельных людей и играет все более важную роль.

Языковая политика обычно определяется, например, в энциклопедиях как совокупность идеологических принципов и организационно-практических мероприятий по решению языковых проблем в социуме, в государстве. Хотя идеологические, политические принципы и соответствующие организационно-практические мероприятия часто связаны с языковой политикой, то не следует их отождествлять или смешивать. Поскольку языковая политика взаимодействует с национальной политикой, естественно, что она в какой-то степени зависит от нее. Но здесь в связи с этим важно в частности обратить внимание на организационно-практические проблемы преподавания в нашей стране иностранных языков и на отношение к ним в меняющихся условиях, возникающих в результате происходивших в последних десятилетиях вообще мирных, хотя в некоторых отношениях почти революционных преобразований, особенно в общественно-политической, экономической и культурной областях.

В лингводидактической области на первый план в этой ситуации выдвинулись международные западные языки. Нет сомнения в том, что начиная с конца XX века и особенно в XXI веке существуют многие убедительные основания, чтобы по ряду внутренних и особенно внешних, т. е. международных, причин и потребностей считать английский язык главным иностранным языком преподавания на разных уровнях системы образования. Важное место в этой системе должны занимать французский, испанский и немецкий языки, но очень трудно объективно обосновать тот факт, что в последнее время русский язык заметно теряет значение и свою позицию в системе польского - все более интенсивного, хотя и уязвимого в некоторых отношениях - языкового образования. Это достойное сожаления явление, по-моему, возникло в результате ошибочного переноса и смешения политики sensu stricto с реально существующим средством общения и важным носителем (каналом) информации, которым является в данном случае естествен- 
ный русский язык, сам по себе не имеющий с политикой вообще ничего общего, но существующий и удовлетворяющий различные информационные и некоторые другие потребности и функции людей независимо от политики и их национальной принадлежности. Но важно понимать, что рассматриваемая возникшая в нашей стране в случае русского языка ситуация явно противоречит нашим различным интересам и потребностям. Ведь хорошо известно, что политика того или иного государства невечна. Обычно она довольно часто меняется. А ситуация, возникшая в результате ошибочного недоразумения, может сказаться отрицательным образом на государственных, общественных, политических, торговых, культурных и других русско-польских и польско-русских отношениях. Правда, случившиеся этого типа ошибки и недоразумения в данной ситуации касаются не только лишь одной польской стороны, хотя это не является каким-либо оправданием. Но ясно, что русский язык, как таковой, здесь ни в чем не виноват. Он является международным средством общения не только на Востоке, но и в какой-то степени на Западе и в других странах. Это также официальный язык заседаний и переговоров ООН, ЮНЕСКО, научных международных конгрессов и конференций, язык богатой литературы, культуры, благодаря исключительно многочисленным переводам текстов, созданных на других, также так называемых редких, малоизвестных языках. Русский язык является источником богатой во многих отношениях информации, т. е. обладает многочисленными достоинствами, важными особенно для жителей стран, соседствующих с Россией, а также стран Средневосточной, Южной и Северной Европы. Понятно, что его усвоение, как и знание любого другого международного языка, является в каком-то отношении обогащением человека. Можно предполагать, что эта неудачная ситуация не имела бы места, если бы в Польше проводилась правильная публичная, объективная, нейтральная языковая политика, которая несомненно являлась бы положительным мотивом (стимулом) и обоснованием, влияющим на выбор русского языка как иностранного в качестве предмета обучения.

Вышеуказанные и другие причины и обстоятельства в значительной степени вытекают также из воздействия различных факторов, влияющих на уровень и характер существующей у нас и постоянно изменяющейся (далеко не всегда в желаемом лучшем направлении) целостной системы образования, а также в определенной степени из недостаточного использования результатов научных исследований в рамках соответствующих фундаментальных, особенно прикладных и практических областей. В связи с этим здесь важно обратить внимание на тот факт, что на протяжении многих десятилетий наблюдается заметное несоответствие, даже расхождение, между теорией и практикой препо- 
давания иностранных языков. Фактическое ощутимое отсутствие попыток проведения экспериментального проверочного тестирования довольно многих предложенных, заслуживающих внимания опубликованных, практически ориентированных теоретических лингводидактических концепций, методов, принципов и - в случае получения положительных результатов тестирования - их внедрения в дидактическую практику не может не сказаться отрицательным образом на уровне владения в нашей стране иностранными языками.

Образованию и существованию такого все-таки неудовлетворительного положения вещей способствует, в частности, тот факт, что среди полученных на почве разных неофилологий нередко интересных и ценных исследовательских результатов в области все более разветвленной и развитой лингводидактической мысли надлежащего внимания, соответствующего лингводидактическим и некоторым другим общественным потребностям, на наш взгляд, все еще требуют и заслуживают также давно уже постулированные нами (с начала 70-х годов XX века) социологические основы преподавания иностранных языков 1. В последующие десятилетия появились связанные с этой проблематикой публикации также других авторов. Поскольку, как известно, язык и речь (т. е. виды речевой деятельности) - это многоаспектные, в значительной степени общественные структурно-системные явления, функционирующие, как правило, в обществе (социуме), возникает вполне закономерный вопрос: почему в науке о преподавании этих явлений - глоттодидактике - не учитываются в надлежащей степени социологический подход и соответствующие ему методы и принципы научного анализа? Может быть, именно поэтому эффективность этого преподавания часто кажется не вполне удовлетворительной.

В предложенном нами и разрабатываемом вместе с другими авторами международном научно-дидактическом проекте, осуществляемом в рамках интегрированной систеты научных основ преподавания иностранных языков, пока еще вполне не разработанные, но по своему характеру всеобъемлющие социологические основы наряду с ведущими и целевыми лингво-дидактическими (т. е. методико-педагогическими) основами выполняют, кроме важных стоящих перед ними собствепнных задач, функции соединяющие (интеграционные) и одновременно синергетические (положительно влияющие друг на друга). В зависимости от практико-дидактических целей, задач и потребностей они профилируют все остальные основы - лингвистические, культурно-реалиеведческие, психологические (и психолингвисти-

\footnotetext{
1 См. информацию об этом в Выступлении в журнале „Język Polski” 1972, nr 1, c. 75-76; см. также нашу вступительную статью в кн.: Podstawy naukowe nauczania języka rosyjskiego, pod red. S. Siatkowskiego, Warszawa 1972, c. 5, 8-9.
} 
ческие), технико-технологические - в общую, комплексную научно-исследовательскую и практико-лингводидактическую стратегическую теорию и практику преподавания (и усвоения) иностранных языков.

Здесь, несомненно, должна давать знать о себе и в значительной степени практически проявляться только что упомянутая положительная (усилительная) синергетика. Благодаря отношениям взаимной дополнительности и возникающих здесь, в частности, синергетических процессов дальнейшая разработка вышеуказанных научных основ по принципу взаимодействия прямых и обратных связей между ними как динамической самоорганизующейся интегрированной синергетической системы может осуществляться мульти-, меж- и трансдисциплинарным образом. При этом должны учитываться разные другие возможности воздействия синергетики, возникающие в процессе все более интенсивного и обогащенного преподавания (и усвоения) иностранных языков и все лучшего использования результатов этого преподавания.

Важно также в рамках социологизации и оптимизации лингводидактической теории и практики рационально использовать все возможности, скрытые в прагмалингвистике и в лингвистической прагмасемиотике, где естественным образом эти взаимосвязанные аспекты наличествуют, с учетом более широкого контекста культурно-общественной семиосферы². Здесь также могут оказаться полезными соответствующие идеи праксеологии, т. е. общей теории рационализации и оптимизации, - науки, начало которой положил в Польше профессор Т. Котарбиньски и которая развивается его последователями. В результате всех этих и, возможно, других усилий разных исследователей, по нашему мнению, должна оформиться и в дальнейшем успешно развиваться - на фундаменте существующей лингводидактики (методико-педагогических основ), возникших и постепенно развивающихся социологических основ языкового преподавания и обучения (аквизиции, усвоения), других вышеупомянутых основ преподавания - объединенная стратегическая социальная лингводидактическая теория, т. е. социальная лингводидактика (в польской терминологии - glottodydaktyka społeczna). Можно надеяться, что всему этому будут способствовать соответствующие актуальные культурно-социальные обстоятельства в условиях существующих цивилизационных революций - научно-технической, технологической, электронно-информационной, промьшленной и, возможно, других.

\footnotetext{
2 В связи с этим см., например, недавно опубликованную нашу работу: S. S i a t k ow s ki, Актуальные проблемы культурно-общественной семиосферы и семиотико-лингвистические исследования, [в:] Zagadnienia innowacyjności funkcjonowania systemu badania + rozwój w nauce, t. II, red. naukowy A. Miklewski, Warszawa 2011.
} 
В связи с вышесказанным следует отметить, что на более широком фоне анализируемых выше вопросов, особенно наиболее широких (всеобъемлющих) по своему характеру объединяющих социологических основ преподавания и усвоения иностранных языков, нуждаются в том или ином, иногда в довольно существенном, пересмотре (и переоценке) другие упомянутые выше, раньше оформившиеся основы или некоторые их аспекты, в том числе, например, считавшиеся до сих пор наиболее важными и прочными констатации лингвистической интерпретации преподавания и аквизиции иностранных языков. Поэтому, наконец, стоит очень кратко остановиться на этом вопросе.

Так, например, укоренившаяся, в частности под влиянием лингвистического бихевиоризма и структурализма, особенно на почве аудиолингвального и других сходных с ним методов, концепция преподавания иностранного языка как тренировки его аспектов, в которой нередко главная роль отводится утомительному и малоэффективному дриллу, в последние десятилетия все больше подвергается пересмотру. Методисты и преподаватели - сторонники этой ориентации или испытавшие на себе ее влияние - часто рассуждают так: Поскольку автоматизировать можно только языковые средства (материальные формы и структуры языка), а не содержание, уместно говорить об аспектной тренировке. Эту тренировку иногда абсолютизируют, тогда она приобретает вид преподавания языка по аспектам, иногда сочетают с комплексной тренировкой, что представляется более обоснованным, если при этом получает соответствующее разрешение проблема включаемости отрабатываемых аспектов в синтаксические структуры и в текст. Однако методические концепции этого типа многое важное упускают из виду или упрощают. Их сторонники, принимая во внимание лишь часть предмета обучения - аспекты языка, недооценивают или, в случае крайних концепций преподавания языка по аспектам, вообще оставляют в стороне весьма существенные для свободного и адекватного владения видами языковой коммуникации межаспектные связи языковой системы, в частности сложные и многогранные взаимоотношения между формальным и семантическим ее планами. Также обычно не учитываются неязыковые аспекты и компоненты социально-речевой реальности ${ }^{3}$ и межаспектно-компонентные связи, характерные для процессов социально-речевого синтеза и анализа (особенно упускаются из виду проблемы обучения синтезу и анализу текста и дискурса). Кроме того, возлагается на плечи самих учащихся усвоение этой,

\footnotetext{
${ }^{3} \mathrm{O}$ социально-речевой реальности более подробно см.: С. С я т к о в с к и й, Проблемы изучения социально-речевой реальности (соииально-речевое интердействие), „Русский язык за рубежом" 1984, № 5.
} 
пожалуй, наиболее трудной части предмета обучения, что представляется лишь частично посильным самым способным учащимся.

В зависимости от конкретных целей и задач преподавания работа над отдельными аспектами языка, особенно фонетическим, или аспектами и компонентами социально-речевой реальности должна занять свое место в целостной системе обучения языковой коммуникации; но ее следует понимать лишь как этап на пути к целостному (комплексному) усвоению видов социально-речевой деятельности и владению ими. Учет аспектной специфики должен всегда предполагать социально-коммуникативные цели и задачи. Такая связь, методически правильно реализованная, может только способствовать усвоению отдельных аспектов языка, специфика которых в полной степени проявляется именно в процессах языковой коммуникации, в натуральном дискурсе. Поэтому даже работа над постановкой и коррекцией произношения отдельных звуков станет более перспективной и эффективной, если она будет лучше связана с такой комплексной тренировкой, которая учитывает естественные для функционирования этих звуков межаспектно-коммуникативные условия и связи.

Созревшая - особенно в недрах классического американского структурализма и глоссематики - лингвистическая концепция, согласно которой язык представляет собой только имманентную структуру элементов, в исследовании которой особое внимание уделялось плану внутренних отношений между формальными (структурными) единицами, тогда как план содержания медленно и с трудом получал „права гражданства” как объект научного изучения, в силу своей неполноты и недостаточной адекватности не смогла, вопреки надеждам и желаниям многих ее сторонников (лингвистов и методистов), „революционизировать" теорию и практику преподавания иностранных языков. Ее влияние на методику, сначала весьма ощутимое, со временем стало бледнеть. И хотя до сих пор обычно считается, что достоянием структурного и аудиолингвального методов являются научно разработанные принципы отбора, презентации и реализации (в виде тренировочных автоматизирующих упражнений) языковых структур, тем не менее эти принципы, представляющие собой, несомненно, определенную ценность, следует рассматривать лишь как часть более широкой методической системы, вмещающей многие другие принципы, методы и подходы.

Таким образом, структурализм, который в науке о языке сыграл весьма существенную роль, в плане лингводидактических приложений его возможности оказались ограниченными, хотя определенную конструктивную роль он играет и в данной области. Приблизительно то же самое, mutatis mutandis, можно сказать о генеративной (генеративно- 
-трансформационной) грамматике и генеративной семантике, во многих отношениях интересных научных направлениях, которые занимают заметное место в истории науки о языке; но их значение для теории и практики преподавания иностранных языков ограничено идеей и моделью лингвистического генеративизма. Правда, в рамках этих направлений, особенно генеративной семантики, удалось установить, вопреки ортодоксальному структурализму, например, весьма ценное и полезное для лингводидактики положение, согласно которому в процессе коммуникации основной генеративной силой обладает семантический компонент, в то время как синтаксический и фонологический компоненты выполняют в значительной степени подчиненные интерпретационные функции. Но, не выходя за пределы генеративизма, не удалось, например, вскрыть механизмы перехода от системы языка к процессам речи (языковой коммуникации), которые лежат за рамками данной модели. И тут весьма важно обратить внимание на положительную роль близкой, даже отчасти совпадающей с социологическим подходом, функциональной стилистики (социостилистики), особенно охватывающей промежуточную зону между языком и речью. Более полное познание этих существенных для социальной лингводидактической теории и практики механизмов и связанных с ними закономерностей и правил процессов речи (особенно дискурсивной) требует выхода за пределы языковых явлений и, следовательно, науки о языке в целом - в разные области взаимосвязанных явлений социально-речевой деятельности, где язык функционирует вместе с неязыковыми явлениями как открытый и закрытый код. Это еще раз подтверждает, что даже самые интересные для науки о языке концепции и теории не в состоянии обеспечить достаточно полную основу для оптимально эффективного решения всех существенных проблем более широкой, особенно предлагаемой социальной теории и практики преподавания иностранных языков, которая имеет, как мы пытались это обосновать выше, интеграционно-междисциплинарный характер.

Итак, по мере развития исследований в рамках социологических основ преподавания иностранных языков, главным образом социальной лингводидактики, изучаемая проблематика будет все более обогащаться, в связи с чем перед теорией и практикой этого преподавания открываются новые широкие перспективы и возможности. В результате эта теория и практика будет становиться гораздо более эффективной и в развивающихся условиях все более оптимальным образом будет учитывать различные актуальные и перспективные потребности функционирования и развития разных областей индивидуальной и общественной жизни. 


\section{Библиография}

С я т к о в с к и й С., Межкультурная коммуникативная компетенциия и социильная ıингводидактика, „Studia Rossica Posnaniensia”, Poznań 2010, z. XXXV, с. 259-266.

С я т к о в с к и й С., Проблемы изучения социально-речевой реальности (соииально-речевое интердействие), „Русский язык за рубежом” 1984, № 5.

С я т к о в с к и й С., Социолингвистика, соииология языка и социология языковой коммуникации, „Русский язык за рубежом” 1984, № 2.

С я т к о в с к и й С., Социология языковой коммуникации и проблемы преподавания иностраннных языкоһ, „Русский язык за рубежом” 1985, № 3.

Elementy realioznawcze i literackie nauczania języka rosyjskiego, pod red. S. Siatkowskiego, Warszawa 1977.

K o s z l a - S z y m a ń s k a M., Realioznawczo-kulturowe aspekty nauczania języka hiszpańskiego, Warszawa 2014.

Nauczanie jezyka rosyjskiego a językoznawstwo i psychologia, pod red. S. Siatkowskiego, Warszawa 1976.

Nauczanie języka rosyjskiego a językoznawstwo i psychologia, pod red. S. Siatkowskiego, wyd. II rozsz., Warszawa 1986.

Podstawy pedagogiczne nauczania języka rosyjskiego, pod red. S. Siatkowskiego, Warszawa 1982.

S i a t k o w s k i S., Актуальные проблемы культурно-общественной семиосреры и семиотико-лингвистические исследования, [в:] Zagadnienia innowacyjności funkcjonowania systemu badania + rozwój w nauce, t. II, red. naukowy A. Miklewski, Warszawa 2011.

S i a t k o w s k i S., O paradygmatach naukowych, [в:] Paradygmaty filozofii języka, literatury i teorii tekstu (pogranicza metodologiczne), pod red. A. Kiklewicza, Słupsk 2004.

$\mathrm{S}$ i a t k o w s k i S., O roli stylistyki w nauczaniu jezyka rosyjskiego, [в:] Problemy nauczania języka rosyjskiego oraz ksztatcenia nauczycieli rusycystów w Polsce. Materiały sesji naukowej, WSP im. Jana Kochanowskiego, Kielce 1990, c. 61-74.

S i a t k o w s k i S., Płaszczyzna przedmiotowa nauczania jezzyka obcego a materiaty glottodydaktyczne (o roli czynników socjalnych w dydaktyce języków obcych), [в:] Z teorii i praktyki tworzenia materiałów glottodydaktycznych, pod red. F. Gruczy, Warszawa 1988.

S i a t k o w s k i S., Wstęp, "Język Polski” 1972, nr 1, c. 75-76.

S i a t k o w s k i S., Wstęp, [в:] Podstawy naukowe nauczania języka rosyjskiego, pod red. S. Siatkowskiego, Warszawa 1972. 
